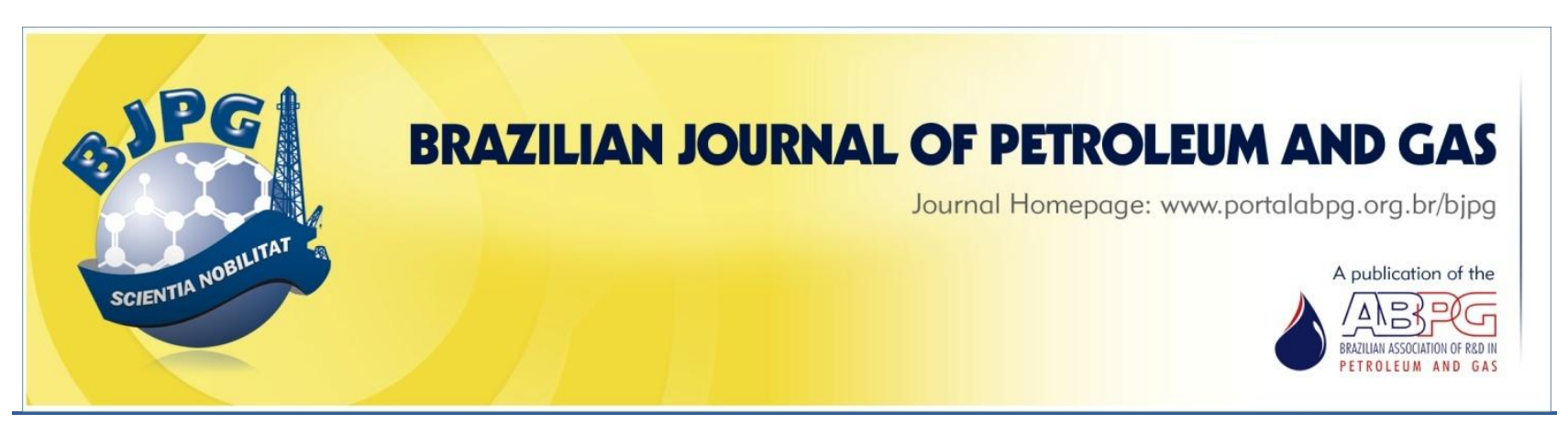

\title{
PRESSURE TEST AFTER WAIT ON CEMENT (WOC): ANALYSIS IN OIL WELL CASING DESIGN
}

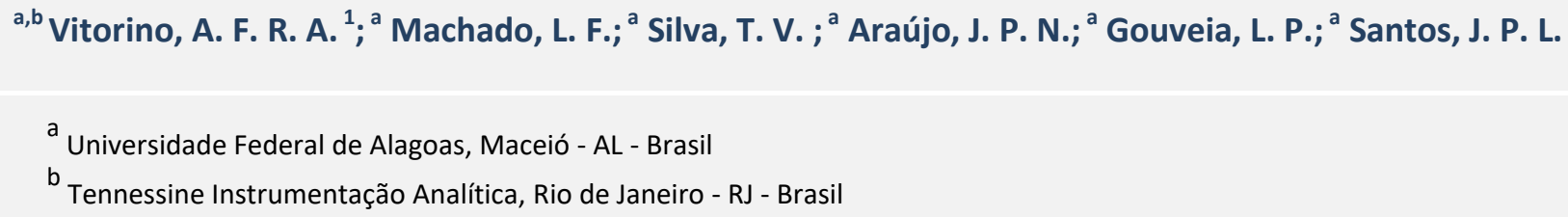

\begin{abstract}
This work discusses the load criteria known as pressure test after waiting-on-cement (WOC) through a detailed explanation of the calculation methodology and study cases. Well casing design is an important step on hydrocarbon exploration planning. New methodologies in this subject allows improvement on well structural integrity combined with time and costs reductions. In routine procedures, design may consider pressure test after WOC, which is an essential operation for cementation failures verification. During test pumping, additional loads are applied to the casing and, when combined, they must be lower than tubular resistances to ensure no failure, avoiding catastrophic consequences. The computational tool CWELL is used for analyzing a production casing string set next to the reservoir, submitted to the pressure test after WOC. Investigating different grades and linear weights on API tubes verifies the achievement of well safety requirements. Results indicate the importance of performing integrated analyzes to guarantee wells stability.
\end{abstract}

\section{KEYWORDS}

cementation; structures; casings; tubes; hydrocarbons

\footnotetext{
${ }^{1}$ To whom all correspondence should be addressed.

Address: Tennessine Instrumentação Analítica, Avenida das Américas, 19005. Bloco: 2, Sala: 429. Recreio dos Bandeirantes, Rio de Janeiro, Rio de Janeiro, Brasil.

ZIP Code: 22790-703 | Telephone: +55 82 99944-0944 | e-mail: felipe.rav@gmail.com doi:10.5419/bjpg2018-0022
} 


\section{INTRODUCTION}

Nowadays, despite the energy matrix diversification, the demand for hydrocarbons continues to increase. This is an indication of the large global dependence on these fuels (BP, 2017). The growing complexity of oil well constructions for deep reservoirs is highlighted. Therefore, projects involving well construction need to be adapted to achieve efficiency in terms of time and cost (Aadnøy, 2010). When evaluating the importance of financial planning in the design of an exploratory program, casings expenses are among the costliest in the development of a well. In some situations, casing expenses account for $18 \%$ of the overall completion costs. If there are failures on the installation process or during the service, repair costs will make these costs even higher (Rahman \& Chilingarian, 1995; Samuel et al., 2014).

Well casings are structures responsible for several functions, such as keeping the well open; preventing undesired fluid exchange between the well and the formation; being the conductor of fluids, from the formation to the surface, during production, and from the inverse path in the injection. Due to these factors, the casings can be considered important for hydrocarbon extraction in a safe and efficient way. The sizing step is one of the most relevant parts of the proper selection process of these components, and it has brought recurring challenges to drilling and completion engineers. This happens because those are

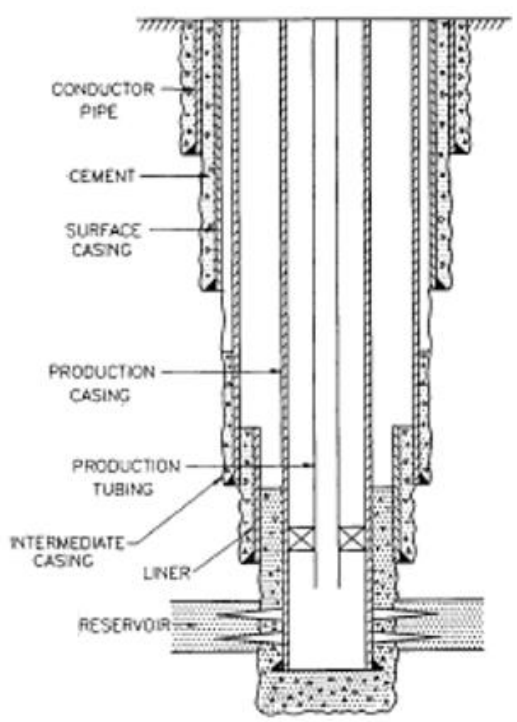

Figure 1. Casing program showing different casing sizes and their setting depths (Rahman \& Chilingarian, 1995). structures that are subjected to different types of loads that may compromise their integrity. The complexity of current wells requires a greater accuracy in the planning of casings, especially for applied load calculations (Rahman \& Chilingarian, 1995; Samuel et al., 2014; Gholami et. al, 2016; Wang \& Taleghani, 2014).

The financial importance of the projects resides on the fact that sizing analyses generate references, including books and technical papers, proposing best practices to companies in oil and gas sector (Aadnøy, 2010; Allomax Engineering, 2000; ANSI/API TR 5C3, 2008; Shahvali et al. 2014, Peng \& Wang 2012, Ma et al., 2009). These materials provide a theoretical basis for several investigations. They guide project improvements, such as the ones proposed by the authors of this in the implementation of a computational tool called Casign Well (Costa, 2016).

Thus, the objective of this is to verify the mechanical integrity of the well casing system by means of the critical forces generated during the wait on cement (WOC) pressure test. This test leads to evaluate the success of the cementation, being a fundamental step for structural evaluation of the well casing section. Based on mechanical integrity indicators, this work proposes the ideal configuration for the production casing system.

\section{METHODS}

The proposed analyses were developed on the software CWELL, which is a web application that performs the study of casing for oil wells. This mechanism was implemented within the Multidisciplinary Petroleum Engineering Applications System (SAEP), developed by the Federal University of Alagoas. The computational tool carries out the detailed analysis of the stability of the columns in several stages of the well (Costa, 2016).

Figure 1 illustrates the production casing. Among different kinds of well casings, it has the function of isolating producing zones to promote control over the fluid from reservoir. It also allows selective production when the well has several producing regions. It is through the production casing that the well completion is done (Aadnøy, 2010). The completeness of this structure depends 
a

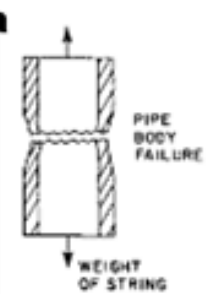

b

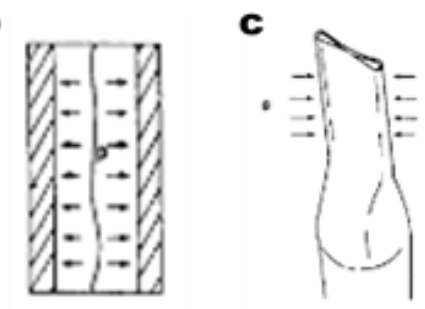

Figure 2. Modes of failures in tubes by: $a$ - tension; $b$ - burst; c - collapse (Bourgoyne et al., 1991.).

on the mechanical strength of the tubular installed. ANSI/API TR 5C3 (2008) standard indicates the calculations of how well the tube withstands different types of stress. The casing must withstand traction or compression, its failure (Figure 2-a) results in plastic deformation due to axial stresses. Similarly, it must withstand the burst produced by the excessive increase of internal pressure against external one (Figure 2-b). It must withstand the collapse, resulting from loads in which external pressure protrudes to internal, as shown in Figure 2-c.

\subsection{Tubes resistance to internal loads}

Equation (1) and Equation (2), respectively, indicate tube resistance to traction or compression $R_{t}$ and to burst $R_{b}$. Tube outer $D_{o}$ and inner $D_{i}$ diameters, as well as its yield stress $Y_{p}$ and thickness $t$ are parts in the equation. The resistances are compared with the applied loads. If they exceed the tube load limit, it can indicate failure. For all types of applied loads, CWELL includes an extra portion to the cargoes. Those are the safety factors, which are common items in engineering projects, bringing them greater reliability, from a percentage increase of the values of loads. These elements vary according to the characteristic design conditions and the company that conducts it.

$R_{t}=\frac{\pi}{4}\left(D_{o}^{2}-D_{i}^{2}\right) Y_{p}$

$R_{b}=2 Y_{p} \frac{0.875 t}{D_{o}}$

Aiming for a more realistic analysis, one must recognize that internal, external, and axial forces, acting simultaneously, can influence each other. Thus, for three-dimensional studies, it is prudent to consider a triaxial analysis, which can be applied through the von Mises plasticity criterion. The equivalent stress, $\sigma_{V M E}$, relates the axial $\sigma_{a}$, radial $\sigma_{r}$, and tangential $\sigma_{t}$ stresses, as presented in Equation (3) (ANSI/API TR 5C3, 2008). The pipe remains in linear elastic regime when $\sigma_{V M E}<Y_{p}$. On the mentioned stresses, it is important to consider that the axial stress is given by the ratio of the axial force to the cross-sectional area of the pipe, since the radial and tangential stresses are given by the Lamé equations for perfect thickwalled pipes (Aadnøy, 2010; ANSI/API TR 5C3, 2008; Bourgoyne Jr. et al., 1991).

$\sigma_{V M E}=\frac{\left[\left(\sigma_{a}-\sigma_{r}\right)^{2}+\left(\sigma_{r}-\sigma_{t}\right)^{2}+\left(\sigma_{t}-\sigma_{a}\right)^{2}\right]^{0.5}}{\sqrt{2}}$

Graphically, it is possible to describe an envelope created by Equation 3 and another one generated by the equations from ANSI/API TR 5 C3 (2008), known as the envelope (API-based security regulatory factors), as illustrated in Figure 3. These envelopes, penalized by the pipe safety factors, are

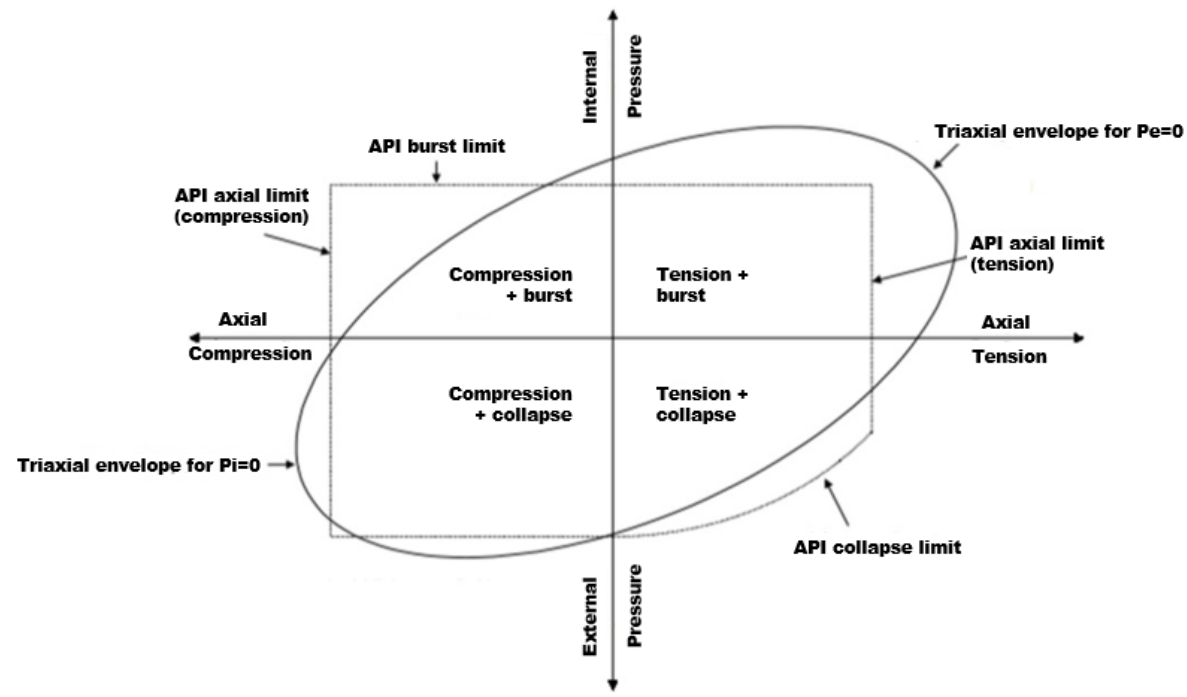

Figure 3. von Mises Ellipse and API Envelope generated for Casing tubes (Costa (2016), adapted). 
basis for analyzing the tube structural safety. In this graphical area, the well loading scenario curves enable a visual comparison between resistance and loads to the pipe. That is, if the curves that represent the load applied to the tubes exceed the envelopes, the casing structural integrity is not guaranteed, since the flow stress of the material is achieved. In this case, one can state that the structural element reached the service limit state. It is worth noting that, even after exceeding these boundaries, the tube can also be used, however imperfectly, until it reaches the ultimate limit state, the structural failure, indicating the final stop of its use.

\subsection{Pressure test after WOC}

As for the axial loads, the string weight $F_{P}$, indicated by Equation (4), and the buoyancy $F_{E}$, indicated by Equation (5), are involved, reducing the weight action. These forces depend on the linear weight of the pipe $W$, in $\mathrm{lbf} / \mathrm{ft}$; the true vertical depth $T V D$, in $m$; the hydrostatic pressure of the drilling mud $P_{m u d}$, in psi; and the external and internal areas, $A_{o}$ and $A_{i}$, in $p o l^{2}$.

$F_{P}=3.28084 W * T V D$

$F_{E}=P_{\text {mud }}\left(A_{o}-A_{i}\right)$

Referring to the study of radial and tangential loads to the tube, the Pressure Test is set up after WOC. This is a test performed as soon as the cementation is completed after reaching the casing shoe, indicating the success or failure of the cement setting in the well. Cementation consists of a cement paste application process with the objective of hydraulically isolating different areas of interest (Bearden \& Lane, 1961; Rabia, 1985). It is worth emphasizing that there are companies that carry out the pressure test of the casing even with the cement not cured (fresh cement), since, in some cases, micro channels have been created between the cement and the casing, allowing communication of the pressure in several areas (Rabia, 2011). During this event, one can interpret the interaction between internal and external pressures.

For the internal pressure $P_{i}$, in $p s i$, one can see the influence, in Equation (6), of the pressure test on surface, $P_{s p}$, in $p s i$, and of the drilling fluid, whose specific weight is given by $\rho_{\text {perf }}$, in $\mathrm{lb} / \mathrm{gal}$, in a certain TVD, in meters) (Allomax Engineering,
2000; Samuel et al., 2014).

$P_{i}=0.1704\left[\rho_{p e r f} T V D\right]+P_{s p}$

External pressure calculation is based on two situations, observing the external pressure $\left(P_{o}\right.$, in psi) applied by the cement after setting. Situation 1- looks at the pressure from the top of the well $\left(T V D_{L D A}\right.$, which corresponds to the water depth in meters) to the top of cement (TVD $D_{\text {cement, }}$ in meters). It follows Equation (7), which involves the action of the drilling fluid and the seawater. Its specific mass is given by $\rho_{\text {sea }}$ (in $l b / g a l$ ). Situation 2- from the top of the cement to the base of the casing, including the specific mass of the cured cement $\rho_{\text {cement }}$ (in $\mathrm{lb} / \mathrm{gal}$ ), according to Equation (8) (Allomax Engineering, 2000; Samuel et al., 2014).

$\begin{aligned} P_{o}=0.1704\left[\rho_{\text {sea }} T V D_{L D A}\right. & \\ & \left.+\rho_{\text {sea }}\left(T V D_{\text {cement }}-T V D_{L D A}\right)\right]\end{aligned}$

$$
\begin{aligned}
P_{o}=0.1704\left[\rho_{\text {sea }}\right. & T V D_{L D A} \\
& +\rho_{\text {sea }}\left(T V D_{\text {cement }}-T V D_{L D A}\right) \\
& \left.+\rho_{\text {cement }}\left(T V D-T V D_{\text {cement }}\right)\right]
\end{aligned}
$$

Depending on the operator, $P_{s p}$ can be considered with values up to $80 \%$ of the burst strength pressure of the lowest grade used in the casing (Rabia, 1985, 2011). However, industry data show that, in robust casings, the suggested pressures are high (since they are survival loads), leading to the use of magnitudes that depend on the service loads that may act over the service life of the casing. Pipe leakage is deemed critical scenario of service, considering that the production casing must be prepared for the tube leakage, which is internal to the casing (Bourgoyne Jr. et al., 1991). In this scenario, the surface pressure value can be determined from Equation (9). In addition to $\rho_{\text {perf }}$, Equation 9 can provide the depth of the investigated casing shoe (TVD shoe, in $m$ ) and the fracture gradient at this point, $\rho_{\text {frature }}$, in $\mathrm{lb} / \mathrm{gal}$ (Allomax Engineering, 2000). The surface pressure test also influences the axial load, generating the stress $F_{s p}$, Equation (10), in psi, adding to the axial stress of the column (Rabia, 1985).

$P_{s p}=0.1704\left(\rho_{\text {frature }}-\rho_{\text {perf }}+2\right) T V D_{\text {shoe }}$

$F_{s p}=P_{s p} A_{i}$

The importance of proper cementation can be reflected in considerations about the damage of 


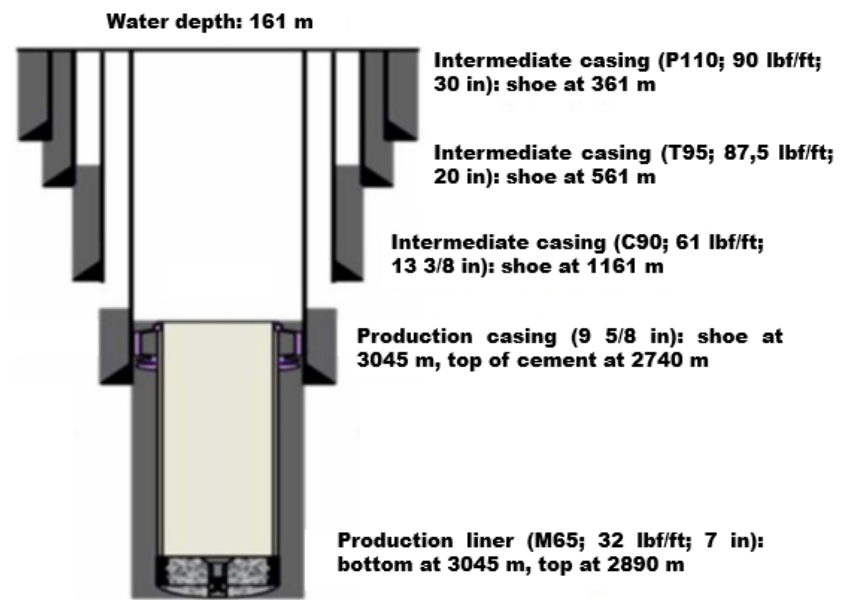

Figure 4. Geometric configuration of the selected well, with the depths in TVD (Perez et al. (2017), adapted).

Brazilian offshore wells. The creation of flow channels in cement, which is one of the safety barriers of the well, allows the leakage of hydrocarbons after the cementation of the production casing. This leakage, besides causing significant economic losses to the company, due to deviation of production and increase of corrosion in some subsurface elements, can generate catastrophic environmental damages, because fluid exchange occurs with the formation (Perez et al., 2017). This work develops the sizing of a production casing adapted from Perez et al. (2017). According to Figure 4, the casing outer diameter is $9.625 \mathrm{in}$. True vertical depths of the top of the casing, the base of the casing, and the top of the phase cement are $161 \mathrm{~m}, 3045 \mathrm{~m}$, and $2740 \mathrm{~m}$, respectively. The well is simplified as vertical.

In addition to the basic data provided, other key information for the project was adopted in works with similar conditions (Allomax Engineering, 2000; Bourgoyne et al., 1991; Rahman \& Chilingarian, 1995), generating the parameters described in Table 1. For this purpose, load calculations are used to optimize casing costs. It is also necessary to investigate the linear weight and the grade (which determines the yield stress of the structure from the material of which it is formed) ideal for the situation, since the lower prices of the pipes are related to the lowest value of grades and the lighter linear weights (Rahman \& Chilingarian, 1995).

Thus, grade $C 90$ and linear weight, $47 \mathrm{lb} / \mathrm{ft}$ (thickness $0.472 \mathrm{in}$ ) were chosen considering their common use in production casing in several projects (Aadnøy, 2010; Allomax Engineering, 2000; Rahman \& Chilingarian, 1995). Based on the standard (ANSI/API TR 5C3, 2008), two other grades (N80 and M65) were tested, submitted to two other linear weights $(43.5 \mathrm{lb} / \mathrm{ft}, 0.435$ in thick, and $40 \mathrm{lb} / \mathrm{ft}, 0.395$ in thick). For all situations, a $12.5 \%$ casing wall thickness penalty was also applied. This penalty is used for casings not characterized as Premium by the manufacturer.

Table 1. Project input parameters.

\begin{tabular}{lc}
\hline \multicolumn{1}{c}{ Parameter } & Value \\
\hline Fracture gradient at 2740 m TVD & $17.08 \mathrm{lbf} / \mathrm{gal}$ \\
Specific mass of the cured cement & $15.88 \mathrm{lbf} / \mathrm{gal}$ \\
Specific mass of the drilling mud & $9.5 \mathrm{lbf} / \mathrm{gal}$ \\
Specific mass of the mixture water & $8.6 \mathrm{lbf} / \mathrm{gal}$ \\
Safety factor for tensile (traction/compression) loads & 1.3 \\
Safety factor for burst loads & 1 \\
Safety factor for colapse loads & 1.1 \\
Safety factor for triaxial loads & 1.25 \\
\hline
\end{tabular}




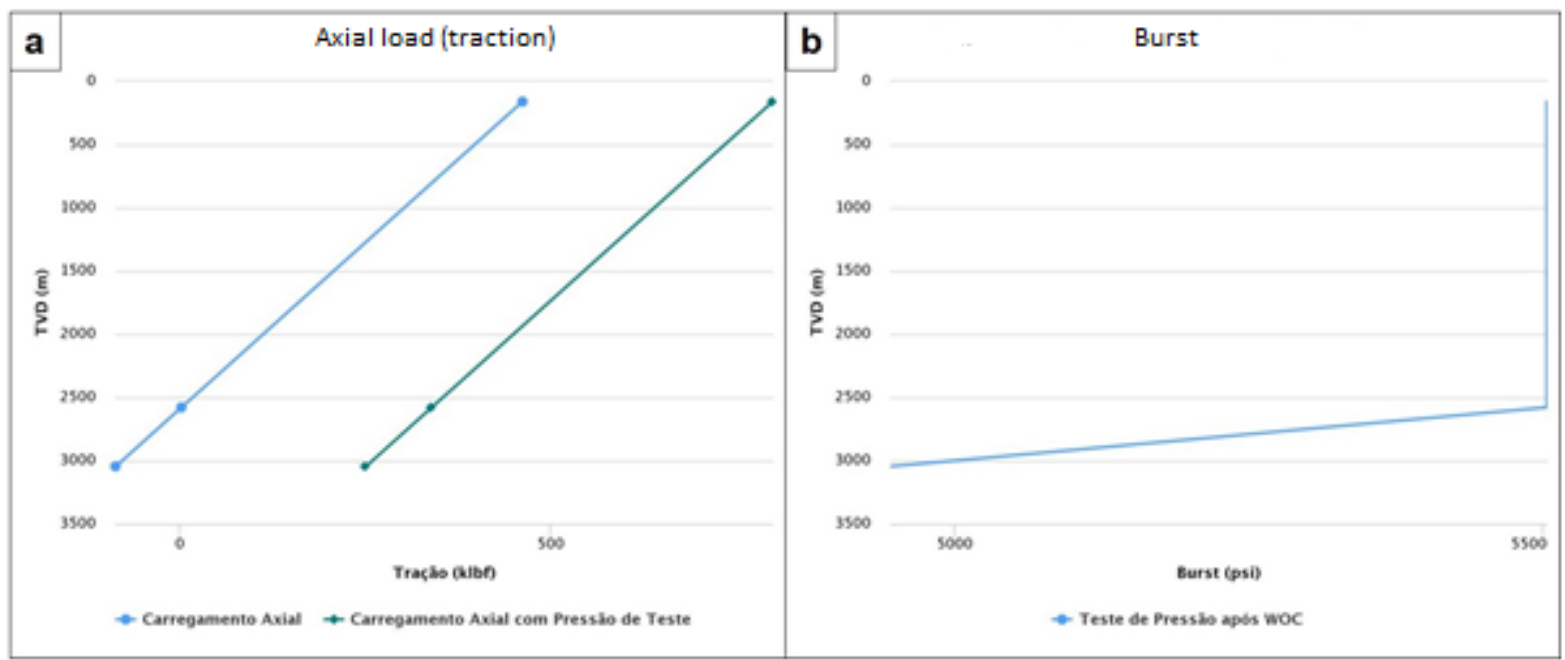

Figure 5. a: Loads representation for traction/compression scenario in tubes with the highest linear weight $(47 \mathrm{lb} / \mathrm{ft})$, i.e. axial load in blue and axial load with pressure test after WOC in green (TVD in $\mathrm{m} x$ tensile load in psi); and b: Loads representation for the burst scenario, i.e. pressure test after WOC in blue (TVD in $\mathrm{m} x$ burst load in psi).

\section{RESULTS AND DISCUSSIONS}

Equation 9 and the input data determined the surface pressure during the test, that is, $4970.75 \mathrm{psi}$. Then, as one can see in Figure 5, graphs were generated for the maximum traction/compression loads on the highest linear weight $(47 \mathrm{lb} / \mathrm{ft})$ pipe and for the burst load applied throughout the well in that order. In Figure $5-a$, the image related to the action of the traction illustrates the major stresses applied in the structure located in the upper part of the well. This was an expected result due to the greater weight in this region. It is worth mentioning that the curve has the same tendency for different linear weights, which, while reduced, generate a lower traction load due to the application of a lower weight. The grade does not influence this value, since it only changes the stress flow (without influencing axial loads). The maximum traction stresses calculated on the surface, in decreasing order, were $798.01 \mathrm{klbf}$ (for $47 \mathrm{lb} / \mathrm{ft}$ ), $770.29 \mathrm{klbf}$ (for $43.5 \mathrm{lb} / \mathrm{ft}$ ), and $743.75 \mathrm{klbf}$ (for $40 \mathrm{lb} / \mathrm{ft}$ ).

For the burst scenario, shown in Figure 5-b, the highest value load for all situations is 5503.17 psi and it is located at the top of the cement, presenting the same value close to the well's head (top of the liner). The curve behaved as expected in literature (Aadnøy, 2010; Allomax Engineering, 2000; Bourgoyne Jr. et al., 1991; Rabia, 2011; Rahman \& Chilingarian, 1995), there was an increase in external pressure from the top of the cement to its base (in the casing shoe) and the burst differential assumed its smallest value.

For comparison, the uniaxial/biaxial strengths are given in Table 2. As expected, the more robust the pipe (either by the grade, leading to increased

Table 2. Results of the uniaxial/biaxial resistances of interest for the tubes analyzed.

\begin{tabular}{cccc}
\hline Steel grade & Linear weight & Tensile resistance & Burst strength resistance \\
\hline \multirow{2}{*}{ C90 } & $47 \mathrm{lb} / \mathrm{ft}$ & $1221.51 \mathrm{klbf}$ & $7723.64 \mathrm{psi}$ \\
& $43.5 \mathrm{lb} / \mathrm{ft}$ & $1130.31 \mathrm{klbf}$ & $7118.18 \mathrm{psi}$ \\
& $40 \mathrm{lb} / \mathrm{ft}$ & $1030.84 \mathrm{klbf}$ & $6463.64 \mathrm{psi}$ \\
\hline \multirow{3}{*}{$\mathrm{N} 80$} & $47 \mathrm{lb} / \mathrm{ft}$ & $1085.79 \mathrm{klbf}$ & $6865.45 \mathrm{psi}$ \\
& $43.5 \mathrm{lb} / \mathrm{ft}$ & $1004.72 \mathrm{klbf}$ & $6327.27 \mathrm{psi}$ \\
& $40 \mathrm{lb} / \mathrm{ft}$ & $916.30 \mathrm{klbf}$ & $5745.45 \mathrm{psi}$ \\
\hline \multirow{3}{*}{$\mathrm{M65}$} & $47 \mathrm{lb} / \mathrm{ft}$ & $882.20 \mathrm{klbf}$ & $5578.18 \mathrm{psi}$ \\
& $43.5 \mathrm{lb} / \mathrm{ft}$ & $816.33 \mathrm{klbf}$ & $5140.91 \mathrm{psi}$ \\
& $40 \mathrm{lb} / \mathrm{ft}$ & $744.50 \mathrm{klbf}$ & $4668.18 \mathrm{psi}$ \\
\hline
\end{tabular}




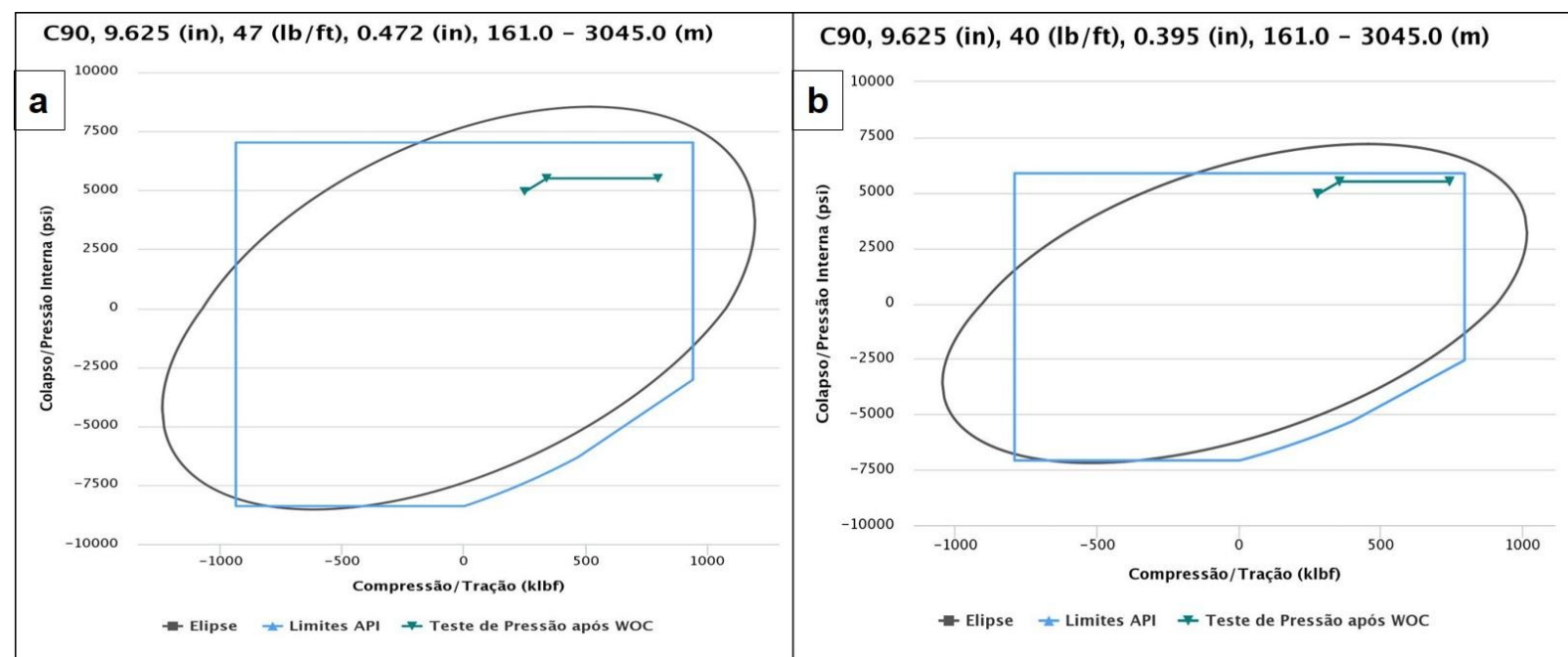

Figure 6. Results of triaxial scenarios for $C 90$ tubes with linear weights $47 \mathrm{lb} / \mathrm{ft}$ (a) and $40 \mathrm{lb} / \mathrm{ft}$ (b) displayed in a tensile load in klbf $x$ collapse/burst strength in psi graph. Black and blue curves stand for VME and API envelope, green stands for the loads.

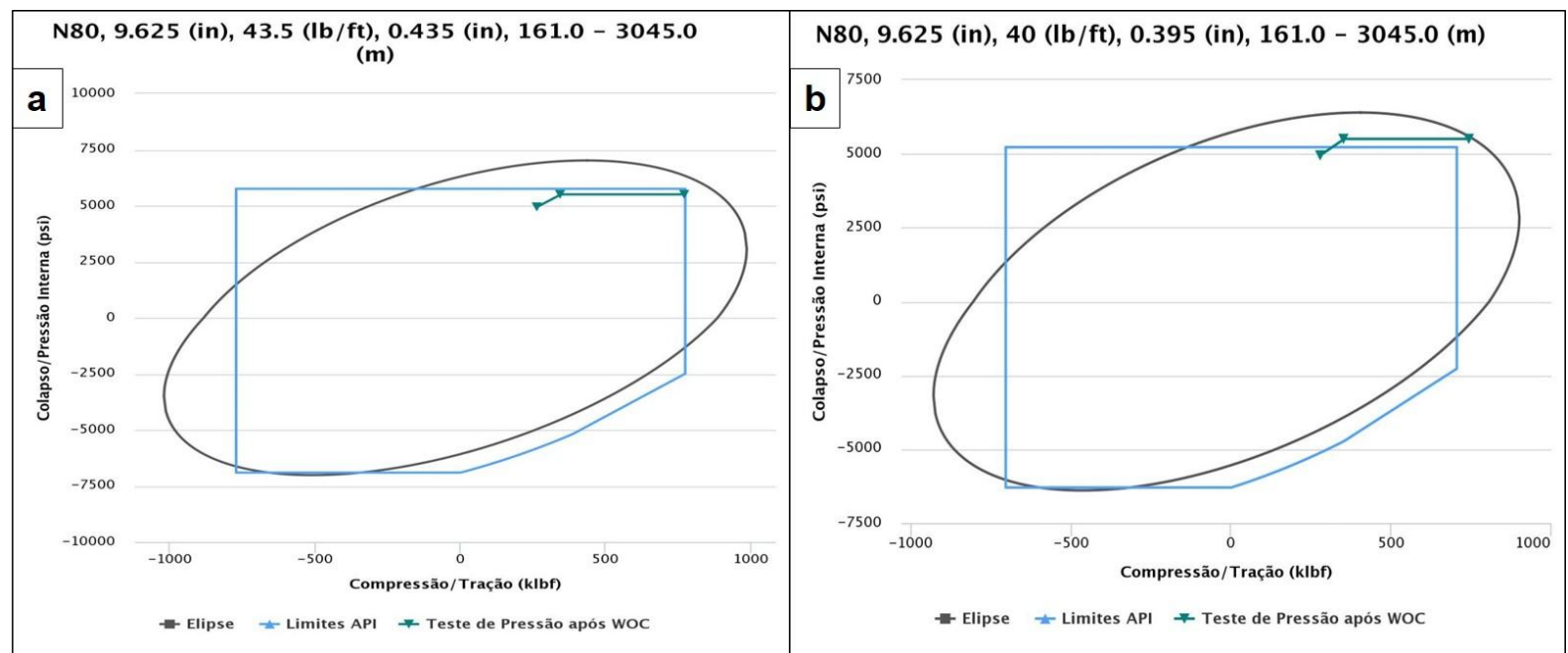

Figure 7. Results of triaxial scenarios for $N 80$ tubes with linear weights $43.5 \mathrm{lb} / \mathrm{ft}$ (a) and $40 \mathrm{lb} / \mathrm{ft}$ (b) displayed in a tensile load in klbf $x$ collapse/burst strength in psi graph. Black and blue curves stand for VME and API envelope, green stands for the loads.

flow stress, or by linear weight, which increases the thickness), the greater the uniaxial/biaxial resistance is, being credited with greater safety in their use. Thus, the most critical values - the lowest strengths - were obtained for M65 casings of $40 \mathrm{lb} / \mathrm{ft}$ and $43.5 \mathrm{lb} / \mathrm{ft}$. Considering the burst failure criterion, one could observe that, for both, the load ( $5503.17 \mathrm{psi}$, like that one shown in Figure $5-b)$ would be higher than its respective resistances (4668.18 psi and $5140.91 \mathrm{psi}$, see Table 2). This indicates the possibility of rupture. It is possible to observe that, in the chosen scenario, these two pipes are no longer reliable for use.

The indication of greater integrity preservation for more robust pipes is maintained in the triaxial study. Figure 6 , Figure 7 , and Figure 8 , in that order, show the triaxial load analyses applied to $C 90(47 \mathrm{lb} / \mathrm{ft}$ and $40 \mathrm{lb} / \mathrm{ft}$ ), $N 80$ (with $43.5 \mathrm{lb} / \mathrm{ft}$ and $40 \mathrm{lb} / \mathrm{ft}$ ), and $M 65(47 \mathrm{lb} / \mathrm{ft}$ and $40 \mathrm{lb} / \mathrm{ft}$ ). In all these graphs, the von Mises ellipse (VME) and API envelope are, respectively, in black and blue colors. If the loading (in green) exceeds any of them, casing failure is indicated. In this investigation, $C 90$ grade pipes proved to be reliable at all linear weights, as seen in Figure 6. Note that envelopes decrease (which makes loading closer to the limits thereof) is evident with the reduction of the linear weight, as with the $N 80$ and $M 65$ casings according to Figure 7 and Figure 8. 


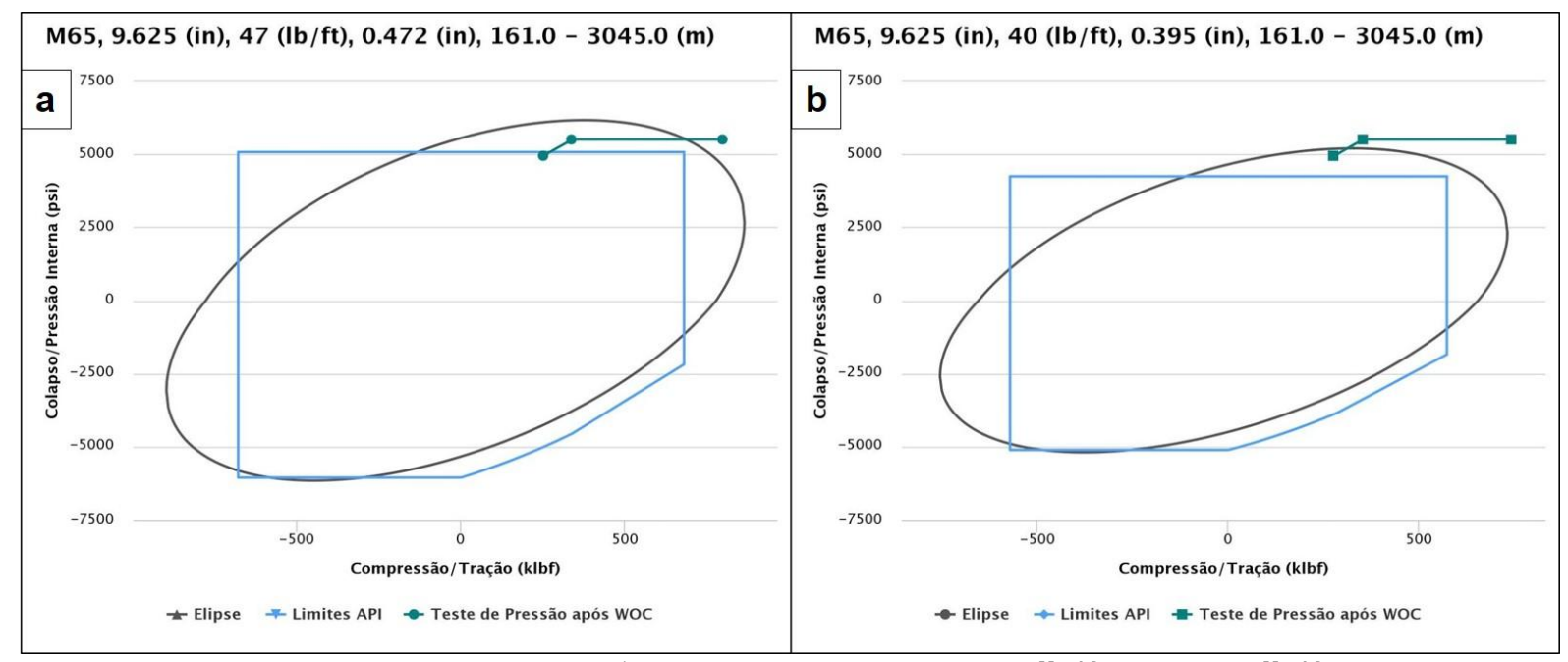

Figure 8. Results of triaxial scenarios for $M 65$ tubes with linear weights $47 \mathrm{lb} / \mathrm{ft}$ (a) and $40 \mathrm{lb} / \mathrm{ft}$ (b) displayed in a tensile load in $\mathrm{klbf} x$ collapse/burst strength in psi graph. Black and blue curves stand for VME and API envelope,

green stands for the loads.

Although more reliable, $C 90$ is usually more expensive than the other tested grades. Thus, Figure 7 shows that under the proposed loading conditions, $N 80$ pipes and linear weights other than $40 \mathrm{lb} / \mathrm{ft}$ are safe. One can observe that the weight of $47 \mathrm{lb} / \mathrm{ft}$ is more robust than that of $43.5 \mathrm{lb} / \mathrm{ft}$ (Figure 7-a), which indicates near, but within limits, loading of the API envelope. It, however, is overcome for the $40 \mathrm{lb} / \mathrm{ft} N 80$ casing (Figure 7-b). A similar situation occurs with the lower grade, $M 65$, combined with the higher linear weight, as seen in Figure 8-a. This indicates that the M65 is unsafe even in the best proposed situations for the chosen scenario. The problem is aggravated when the loading almost surpasses the von Mises envelope where the linear weight is reduced as shown in Figure 8-b.

Thus, it is evident that $C 90$ tests proved to be safe, whereas the casing that would be more financially viable (M65) in the triaxial analysis was not reliable. In the case of $N 80$ tubes, it is demonstrated that, due to their limitations, some applied forces, especially in a situation of low linear weight added to the thickness penalty, can make the use deficient when exceeding the limit state of service. Thus, the pipe can still be used, but inadequately, until the ultimate limit state is reached. The scenario chosen was limited to only one specific situation of the industry (pressure test after WOC), and other efforts could be made to render the intermediate grade completely useless.

\section{CONCLUSIONS}

The developed study indicates the most suitable pipes for the evaluated scenario among the options available. Grade $C 90$ pipes was indicated by the literature for the analyzed situation. However, $N 80$ pipes, less costly than the previous one, presented conditions of safe use, given the proposed scenario. To complement this work, new field scenarios and/or phases should be applied and investigated to address other possible scenarios. In addition, determining the ultimate limit state conditions of the structure would make it possible to determine more accurately how long the pipe could withstand, even with inadequate use due to imperfections along the structure.

Even so, it is evident the possibility of optimization in the use of casings based on their dimensions. Therefore, there is a possibility of an effective creation of a global well project with low costs that can also guarantee the structural integrity of the well. Thus, the industry can profit from the results, and, at the same time, can reduce potential damages caused by the oil and gas sector, benefiting society and the environment.

\section{ACKNOWLEDGMENTS}

The authors would like to thank the Laboratório de Computação Científica e Visualização (LCCVUFAL) and its main institution UFAL, the Conselho Nacional de Desenvolvimento Científico e Tecnológico (CNPq) and Fundação de Amparo à Pesquisa do Estado de Alagoas (FAPEAL) for 
funding and research support along the SAEP project development.

\section{NOMENCLATURE}

$A_{i}$ - Internal area

ANSI - American Nation Standards Institute

$A_{o}$ - External area

API - American Petroleum Institute

CWELL - Casing well

$D_{i}$ - Inner diameter

$\mathrm{D}_{\mathrm{o}}$ - Outer diameter

$\mathrm{F}_{\mathrm{a}}-$ Axial force

$\mathrm{F}_{\mathrm{E}}$ - Buoyancy

$\mathrm{F}_{\mathrm{p}}$ - Casing string weight

$F_{s p}$ - Surface pressure test influence over axial load MASL - Meters above sea level

$\mathrm{P}_{\mathrm{i}}$ - Internal pressure

$P_{\text {mud }}-$ Hydrostatic pressure of the drilling mud

$P_{0}-$ External pressure

$\mathrm{P}_{\mathrm{sp}}$ - Pressure test value on surface

$\mathrm{R}_{\mathrm{b}}$ - Resistance to burst

$\mathrm{R}_{\mathrm{t}}-$ Resistance to tension or compression

SAEP - Petroleum Engineering Applications System

$\mathrm{t}$-Thickness

TR - Technical report

TVD - True vertical depth

$T_{V D} D_{\text {MASL }}-$ Water depth in meters

$T_{V D} D_{\text {cement }}-$ True vertical depth of the top of cement

$\mathrm{TVD}_{\text {shoe }}-$ Casing shoe depth

VME - von Misses ellipse

$W$ - Linear weight of the pipe

WOC - Wait on cement

$Y_{p}-$ Yield stress

$\rho_{\text {cement }}-$ Specific weight of the cement

$\rho_{\text {fracture }}-$ Fracture gradient

$\rho_{\text {mud }}-$ Specific weight of the mud

$\rho_{\text {sea }}$-Specific weight of the sea water

$\sigma_{a}-$ Axial stress

$\sigma_{\mathrm{r}}-$ Radial stress

$\sigma_{\mathrm{t}}-$ Tangential stress

$\sigma_{\mathrm{VME}}-$ Equivalent stress

\section{REFERENCES}

Aadn $\varnothing$ y, B. S. Modern well design. 2nd. ed. Londres: CRC Press/Balkema, 2010.

https://doi.org/10.1201/b10431
Allomax Engineering. Drilling and Production Operations: Casing Design Manual. Aberdeen: Offshore Design Limited (ODL), 2000.

ANSI/API TR 5C3. Technical Report on Equations and Calculations for Casing, Tubing, and Line Pipe Used as Casing or Tubing; And Performance Properties Tables for Casing and Tubing. Washington: American Petroleum Institute, 2008.

Bearden, W. G.; Lane, R. D. Engineered Cementing Operations to Eliminate WOC Time. Engineered Cementing Operations to Eliminate WOC Time. American Petroleum Institute, API-61017 p. 17-26. Tulsa: API Mid-Continent District, Division of Production, 1961.

Bourgoyne Jr., A. T.; Millheim, K. K.; Chenevert, M. E.; Young Jr, F. S. Applied Drilling Engineering. Second ed. Richardson: CCopyright 1991 by the Society of Petroleum Engineers, v. 2, 1991.

BP. BP Energy Outlook 2017. Available at: $<$ https://www.bp.com/content/dam/bp/pdf/energ y-economics/energy-outlook-2017/bp-energyoutlook-2017.pdf>. Acessed on: 18 April 2018.

Costa, J. C. H. Sistema de Aplicações de Engenharia de Petróleo (SAEP): Módulo Poço. Maceió: Universidade Federal de Alagoas, 2016. (in Portuguese).

Gholami, R., Aadnoy, B., Fakhari. A thermoporoelastic analytical approach to evaluate cement sheath integrity in deep vertical wells. Journal of Petroleum Science and Engineering, v. 147, p. 536546, 2016.

https://doi.org/10.1016/i.petrol.2016.09.024

Ma, Y., Yao, K.-Q., Chang, H.-Q., Li, Z.-Y., Guo, X.Y., Shi, Q., Yang, G., Li, W. Technology of improving the quality of casing tie-back cementing in highpressure gas wells. Natural Gas Industry, v. 29 (2), p. 61-63+136-137, 2009.

Perez, M. V.; Melo, J.; Blanc, R.; Jones, P. Epoxy resin helps restore well integrity in offshore well : Case history. Offshore Technology Conference, OTC-28124-MS. Rio de Janeiro: Offshore Technology Conference, 2017.

Rabia, H. Oilwell drilling engineering: principles \& practice. First ed. Londres: Graham \& Trotman Limited, 1985. 
Rahman, S. S.; Chilingarian, G. V. Casing design: Theory and practice. Amsterdam: Elsevier Science B. V., 1995.

Samuel, R.; Wang, Z.; Kumar, A.; Gonzales, A. Improved Model for Tapered Casing Design under Pressure Testing. SPE-167955-MS, 2014 IADC/SPE Drilling Conference and Exhibition, Fort Worth, 2014. https://doi.org/10.2118/167955-MS

Shahvali, A., Azin, R., Zamani, A. Cement design for underground gas storage well completion. Journal of Natural Gas Science and Engineering, v. 18, p. 149-154, 2014.

https://doi.org/10.1016/i.jngse.2014.02.007
Wang, W., Taleghani, A.D. Three-dimensional analysis of cement sheath integrity around Wellbores. Journal of Petroleum Science and Engineering, v. 121, p. 38-51, 2014. https://doi.org/10.1016/i.petrol.2014.05.024 